\title{
Fortress UK? Gated Communities, the Spatial Revolt of the Elites and Time-Space Trajectories of Segregation
}

\author{
ROWLAND ATKINSON \& JOHN FLINT \\ Department of Urban Studies, University of Glasgow, UK \\ [Paper first received 27 October 2003; in final form 9 June 2004]
}

\begin{abstract}
Anecdotal evidence suggests that 'gated communities' are growing in popularity. This paper uses empirical evidence to profile the location and characteristics of gated development in England and details the relative integration of residents. The paper also attempts to think through the wider theoretical and urban policy impacts of gating. In contrast to the view that gated communities provide an extreme example of residential segregation we go further and argue that the time-space trajectories of residents suggest a dynamic pattern of separation that goes beyond the place of residence. Gated communities appear to provide an extreme example of more common attempts by other social groups to insulate against perceived risk and unwanted encounters. Patterns of what we term time-space trajectories of segregation can thereby be seen as closed linkages between key fields, such as work and home, which enable social distance to be maintained and perceived risks to be managed by elite social groups. We conclude that gated communities further extend contemporary segregatory tendencies in the city and that policy responses are required which curtail the creation of such havens of social withdrawal.
\end{abstract}

KEY WORDS: gated communities, segregation elites

\section{Introduction}

Gated communities have begun to creep on to the policy agenda in the UK. Gated communities can be defined as walled and gated residential developments that restrict public access and these attributes have often sparked debate about their desirability or legitimacy in an open society (a forthcoming special issue of Housing Studies will be devoted to these debates early next year). Existing accounts of gated communities (hereafter GCs) have considered their internal socio-legal foundation (Blakely and Snyder, 1999), governance (McKenzie, 1995) and the impact on their residents (Low, 2003). However, in the UK very little is known about them though there has been critical commentary on their undesirability should they increase in number (Minton, 2002). In this context this paper has two key aims. First, to broaden our knowledge of the nature and extent of GCs in England and, second, to provide an early challenge to the idea that GCs represent a communitarian ideal or private choice which lacks wider social repercussions. 
Extreme segregation in US cities has often been seen as a social problem through which social disintegration, low affiliation and social conflict have been engendered (Fainstein et al., 1992; Massey \& Denton, 1993). Segregation has been seen as a product of both income inequalities and discriminatory filters that allocate people in uneven concentrations across the city. Weaker income inequalities and an urban history which has broadly lacked such racial overtones partly explain why segregation is generally lower in the European context (Friedrichs, 1998) and why it has received less political attention. However, while segregation is generally lower in European cities, some writers have argued that the costs of segregation are pronounced for poorer households, including the possibility that living apart produces preconditions for countercultures with norms and values that do not emphasise work or education (Musterd \& Ostendorf, 1998).

The 'area effects' debate has generally been concerned with the additional impacts on life-chances that poor residents face through living in poor areas (Atkinson \& Kintrea, 2002, 2004; Ellen \& Turner, 1997). However, what is notable about existing treatments of segregation and concentrated poverty is that there has been almost no consideration of the social costs imposed through elite and middle-class groups living in similarly 'ghettoised' concentration. This paper raises this issue, suggesting a shift in the focus of studies of segregation and a much greater consideration of the dynamic flows of everyday life both within and outside the field of residential interaction and lived experience. In short, segregation needs to be considered both in its daily dynamism as well as its static residential manifestations.

\section{Segregation and Seclusion in the City}

While various 'defended' territories exist in cities such as gang 'turf', ethnic enclaves, gentrified neighbourhoods and areas of religious significance, gated communities provide a force for exclusion in new and different ways to earlier forms of residential patterning. A long-standing interest in segregation (Peach, 1996) stems from a general presumption that it is a negative phenomenon but what is the implication of segregation if this is extended and played out in the movements and patterns of social interaction in the city? In other words, what if segregation can be conceived of as having a space-time trajectory as well as a residential element? We suggest that the impacts of GCs are far greater than the fact that the affluent might simply live apart from a wider 'mass'. The absence of the affluent from many aspects of city living creates a wider problem for those concerned with the quality of civic spaces and institutions.

In general cities characterised by impermeability and residential location based on key attributes of social difference (most often income or ethnicity) are contrasted with a notion of the 'good city' in which Bridge \& Watson (2000) see 'open, civilising and democratic possibilities'. Everyday exposure to difference has been argued to be a key aspect of socialisation and to participatory modes of governance (Sennett, 1970, 1977; Amin et al., 2000). However, more recent commentaries on urban form, infrastructure and networking (Graham \& Marvin, 2001) have described the connected seclusion of spaces provided for hypermobile upper income groups in the global urban context. 
Graham and Marvin argue that as fortified residential and work spaces are connected by private roads, private shopping streets and malls, closed circuit television (CCTV) and transportation, new secessionary spaces have been created which allow unfettered movement of the affluent in which a:

set of processes are under way within which infrastructure networks are being 'unbundled' in ways that help sustain the fragmentation of the social and material fabric of cities. (Graham \& Marvin, 2001, p. 33)

We argue here that this view of a 'splintering urbanism' is a useful lens to view the changes engendered by an increasing number of gated communities in the UK.

Gated communities suggest that residential segregation does more than simply lead to a withdrawal of certain groups into spatially fixed enclaves. The paper examines the impacts for public service providers and policy-makers related to gated developments. We also extend our analysis to consider the potential for a dynamic, overlapping and fluid sense of segregation and its impacts. In essence we argue that gated communities provide a refuge that is attached to social networks, leisure, schooling and the workplace via paths which are used to avoid unwanted social contact. Our argument is that each of these spaces more or less segregates its occupants from social contact with different social groups, leading us to suggest that the impact of such residential division resembles a seam of partition running spatially and temporally through cities, what we term time-space trajectories of segregation.

Auge (1995) has argued that non-places, including airports, supermarkets, hotel lounges and shopping malls, provide a sense of travelling without moving by virtue of the serial similarity of such spaces. Auge considers the example of an anonymous businessman moving from his home to the airport, a large simple building, from which he travels to another similar airport and stays in a hotel much like those in his home town. Such non-places can also be seen as the protected and detached world of international and local elites moving through space without contact with other social groups.

Other conceptualisations may usefully be attached to those of Auge's thesis. Hannigan's (1998) 'fantasy city' suggests that at the heart of current imperatives of city development is the desire for experience without danger leading to the creation of what Goldberger (1996) has termed 'urbanoid' spaces-spaces which look 'real' but are devoid of the diversity that they used to support. It is now possible for social factions to exercise unprecedented control over their experience of the city in terms of to whom, how and when social encounters are made. Such trajectories of segregation extend patterns of residential separation so that socialisation, work and leisure may be viewed as bounded activities that may have negative impacts on wider social cohesion and our experience of diversity. In short, how is empathy for inequality and social problems engendered if it is never or rarely experienced?

Sennett (1970) and Lasch (1996) have both suggested that the city is the site of a retreat by political and social elites away from the city into their own enclaves and out of the social life of the city. Richard Sennett argues that:

the realm of the city where ... dissonances and conflicts are played out among strangers has been 'abandoned' to the middle and lower classes. I use the word 'abandoned' because the signal feature of the new elite 
in these cities is that it has withdrawn from the public realm. (Sennett, 2001, p. 181)

Sennett argues that the 'new' elites do not seek to engage in the political and social life of the city in ways that those of earlier cohorts did. The street and the city, as an essential aspect of identity, he contends, are being eroded. If we unpack this line of thinking further we may argue that while political and social elites often still work and 'play' in the city their presence is less discernible and, at times, almost invisible or highly secluded.

An important element of this withdrawal is a wider search for security (Low, 2003). As safety has increasingly shifted from being a social good to a commodity (Hope, 1995), differential access to resources contributes to security differentials which manifest themselves spatially as elite groups seek to inhabit 'security enclaves'. Such 'enclaves' offer security through 'bubbles of governance', in which security technologies are purchased and deployed around a 'defensive exclusivity' aimed at insulating communities from dangerous outsiders (Reiner, 1992; Shearing, 1995; Crawford, 1997; Girling et al., 2000). Gated communities appear as the crystallisation of such processes.

The paper is presented in three sections. The first details what we see as the key theoretical hallmarks by which residential segregation and dynamic flows of separation can be understood in the contemporary city. The second draws on the empirical results of recent research on the numerical significance and location of gated communities in England, supplemented by a discussion of their local impacts. Finally this material is drawn out in its implications for understanding a dynamic conception of segregation extending beyond residential location. We conclude by considering the significance of these developments for those left outside the gates and for policy-makers.

\section{The Key Features of Gated Communities in England}

Our operational definition of gated communities was as follows: Gated communities are residential areas or a development that is fenced or walled-off from its surroundings, either prohibiting or controlling access to these areas by means of gates or booms. The concept can refer to a residential area with restricted public access (other terms include-security villages, fortress neighbourhoods, exclusive leisure developments and so on). The research comprised a postal and telephone survey of all of the local planning authorities in England (383), which achieved a 93 per cent response rate.

A series of key actor interviews were conducted with national housing, builders, estate agents and developers' representative groups, architecture and planning bodies, local government organisations and other interested organisations totalling nine interviews. Finally, case studies were undertaken at ten gated sites within four authorities identified through the postal survey returns. These involved structured observation during visits and interviews with the following in each area:

- Gated community tenant/resident association chair

- Representative of tenant or resident association (i.e. non-gated and adjacent area)

- Representatives from the local authority: 
-Planning

-Housing

-Environmental services

- Community police

- Developers of gated communities in the locality

- 'Mystery shopping' calls to sales offices (to establish envisaged community profile and criteria for residency)

An analysis of the legal documentation for GCs from these developers was also carried out. The case study areas were as follows:

1. Metropolitan borough-London borough of Lambeth

2. A large 'provincial' town-Oxford City

3. Commuter belt London-Runnymede, Surrey

4. A northern town-Chester le Street, County Durham

It should be noted that all of our case studies had gates and walls with punch code and/or key entry systems. Only in the Surrey GCs did we find additional guards while one of the Lambeth GCs had CCTV. Built form varied considerably, three of the GCs were large converted homes while five consisted of new-build development that had put gates in place. In Lambeth and Chester le Street the GCs were not in suburban locations with some interviewees suggesting that the security of gating helped to sell the developments in what were perceived to be unsafe areas.

Through the survey research we identified around 1,000 gated communities in England. These developments are generally small (most less than 50 units) but are spread well across England, though they are clustered and more extensive in the South East. A large number of factors were posited as explanations of gated communities as places of residence amongst those seeking to purchase or rent property. Case study interviews suggested that GCs are appealing to a diverse spectrum of households. While a common characteristic of these developments is the relative expense of acquiring a property within them, thereby resulting in a predominance of wealthy individuals, the communities appear to have both young professional and retired elderly residents and also a mix of single, couple or family households.

\section{Motivations to Move to Gated Communities}

The perceptions of local authority officers, national housing organisations and, to an extent, developers, attributed security and exclusivity as the two most important aspects driving demand for gated developments. A number of planning officers identified a growing demand for what one termed total and absolute security'. This was regarded as being influenced by the US housing market, and in response UK developments were being deliberately designed as 'safe and predictable islands of safety'. One community police officer reported that residents of the gated communities in his operational area regarded the surrounding neighbourhoods as crime-prone localities, despite the fact that they had very low crime rates. Significantly none of the national bodies we interviewed had any clear policy position on GCs and were generally ambivalent about their positive or negative qualities, beyond operational difficulties arising from their lack of permeability. 
It is important to recognise that security is not aimed solely at protecting residents against serious crime but also meets an apparent desire to avoid day-to-day incivilities and random social contact. Interviewees both inside and out of the GCs felt that distinction and a sense of exclusivity were equally, if not more important, than safety concerns in explaining the attraction of GCs. It is apparent that developers themselves attach a growing importance to building gated developments, and wish to build such communities where possible, as a representative of one national developer explained:

Gated communities are very important in the overall development market. In all developments there is a preference to gate, even if it is just car parking spaces. If possible, we do try to get planning approval for gated living. (Developer 2)

However, choices about location were still driven by traditional concerns such as the proximity of employment centres and desirable schools as well as the additional security measures offered by these developments.

While security was an important factor in the choice to live in a gated community, and residents reported that 'feeling very safe', and 'living amongst fellow professionals' were major benefits of their residential location, the case studies indicate that the desire for privacy amongst residents of gated communities was as important as a fear of crime in informing residential choice. Thus, security systems are utilised as much to preserve anonymity as to protect from criminal activity. In interview one resident reported that many of his neighbours requested gatehouse personnel not to confirm any enquiries about their residence in the development.

Other motivations given for living in the developments included the value for money that properties offered, given their location in affluent and sought-after residential locations, and their potential as longer-term investments given the expected resale prices they may command. The quality of leisure and shopping facilities available in some gated communities, and the fact that these could be accessed 'on-site' was given as a further motivation to residents.

\section{Fear and Sensitisation to Crime}

From some GC residents we found that the apparent safety afforded by gated development did not necessarily translate into a reduction in the fear of crime. In some ways we saw an increased sensitivity to problems, or at least their changing relativity. Some residents spoke of a fear of neighbouring council estates and rowdy youth with one mentioning an attempt by local youths to get into the GC. Other examples included a desire for increased security measures including the closure of gates that might be otherwise open during the day, more CCTV and lighting. Indeed, fear of outsiders appeared to increase for some:

It is not a high crime area, but gated development residents' perceptions are that there is a lot of local crime and they feel more secure in their gated environments. They wish to protect themselves and provide security and equally importantly, privacy. Many residents are celebrities and stars and so privacy is as important to them as security. (Environmental Health Officer) 
Another resident pointed out that 'there are concerns about how safe the community actually is and there is a lack of police presence'. Substituting non-gated for gated residency did not necessarily lead to a reduction in anxiety, such findings are strongly echoed by Low's work in the USA (Low, 2003). It seems possible to connect gated development with a social ecology built on fear (Davis, 1998) but it is also an ecology deeply imbued with a wider emotional set of responses that include safety and insulation, control and privacy.

From this it would seem to be that perceptions, rather than any form of objective data, are; (a) driving GC development and (b) driving the wider rationale that developers may be broadcasting that areas are unsafe and that GCs respond to people's insecurities. Most importantly this creates a driver for developers to act as parties interested in promoting the fear of crime both to justify development and attract their customer base:

These people are seeking to escape the community. Demand is increasing, it's disgusting, a cheap and easy way of marketing on the back of a fear of crime. (Planning Officer)

\section{Communitarian Oasis? Social Relations in the Gated Communities}

Although GCs are often portrayed commercially as sites for fostering internal social cohesion, we found several examples of internal conflict (both between residents and between residents and management companies) within the GCs. Beyond overt conflict within the community we also detected more concealed sets of division. In one case study we found shared-ownership housing internally segregated within the development while residents in the top-end of the market in another case study spoke of cliques existing between neighbours. This could be based on ethnic, status or political lines:

Many residents are not interested in understanding their 'English' neighbours, and tend to stick within national groups, both inside and outside the development.... There is some community spirit, but there are also a number of cliques and cliques within cliques. Groups of people within the community tend to associate with one another, for example all the US citizens. There is less interaction between these groups. (Resident of gated community)

We see issues here that similarly arise in other 'communities'. However, the existence of a management board within gated communities acts as an additional layer of governance (somewhat contradictory for a group with a strong desire for personal autonomy). We felt able to link the growth of GCs in general to privacy and security. However, it would also seem that the freedoms associated with GCs are simultaneously undercut by the socio-legal covenants and rules of the contracts signed upon moving in for the GC management boards and local community strictures about acceptable conduct. In one case a resident of a GC recounted receiving a lawyer's letter asking for toys not to be left on the front lawn.

\section{Permeability and Movement}

A problem identified by local authority officers and the various national bodies concerned the wider impact of GCs on the character of the local streetscape. In 
particular they identified a loss of permeability from gating and walling which led to exclusion of the general populace and increased journey times around GCs and the privatisation of previously public spaces. These concerns were elaborated with a mixture of feelings. For example, while the Council for the Protection of Rural England (CPRE) felt that GCs might alleviate pressure on greenfield sites they also argued that:

Social exclusion and tensions are obvious downsides, they also make transport and urban form more problematic since GCs prevent permeability. We are strongly opposed to gated communities for a variety of reasons - they do not contribute to mixed communities which allegedly promote sustainability, they may exacerbate social tensions and they act against permeability (ease of movement) in urban areas. We don't think that gated communities contribute to raising design and environmental standards in new development which will be essential to meeting wider objectives such as conserving natural resources, creating sustainable communities and contributing to a high quality public realm. (Policy officer, CPRE)

Not only are GCs viewed as a built form that threatens community sustainability but they are further perceived as an incongruous architectural anomaly. One planner described GCs as 'sod off architecture' while other local authority officials regularly commented on the unnecessary fortified look of GCs, often in areas that have low crime rates or in areas where such designs were not in sympathy with the existing character of the street. Here we found what might be seen as a harmful symbolic aspect to GCs that were seen to be divisive by large numbers of planners and outside residents in particular.

Despite security being a prominent marketing feature, gating itself appeared to diminish or hinder access by public support services, particularly environmental services and policing. As one police officer observed: 'the main problem is that when anyone in the development rings to call out the police the gates are locked and we need to get the security codes to gain access'. Even in the dealings of some residents with ancillary services this was carried out by proxies, legal representatives, in a way which extends Baumgartner's (1988) notions of moral minimalism. Moreover there was some resentment and apparent conflict between the residents of some of the GCs and the providers of local services. One officer outlined these difficulties in detail:

If anything annoys them, they expect it to be dealt with straight away. They are not concerned about how it is dealt with, they just expect it to be resolved immediately. There is very much a 'them and us' attitude. Often there is not personal contact with residents. Rather it is often through their solicitors. The first the department knows about a problem is a legal letter. The smaller gated developments, which are like Fort Knox, which have unmanned electronic gates are very difficult to gain access to. This causes problems for environmental health officers, for example when they try to respond to a noise nuisance complaint. (Environmental Health and Services Officer) 


\section{Neighbourhood Relations and Integration}

The research found significant evidence that GCs were perceived to be separate from their 'local' communities from local planners and outside residents. However, in the most affluent examples the social distance between inside and outside the gates was insignificant. Perceptions of the impact of GCs on local community relations ranged from anger and resentment to the view that there was a nil contribution to the wider local economic and social context. As one local police officer for a particularly large and affluent GC noted:

there is also the look of them as 'pens'. It is almost a big brother approach, like the 51st state. Overall, there has been a negative impact. It is very much a separate community whose residents use their own [private] schools and shops. It is very much people coming into the country and then living in their own small, isolated island community. There is very little interaction with other local residents, and it has not brought social or economic benefits. (Community Police Officer)

The impression of islands of social difference and affluence was described by one local resident of an adjacent neighbourhood as 'rubbing our noses in it' by creating highly visible segregation at a local level. While it may be that some local residents disliked new outsiders more generally, the existence of gating appeared to solidify such views, as one non-gated resident described:

The gated community is very different to the places other people live in around here. The people in it are young professionals without children, outsiders to the town. They are obviously wealthy and they have that on display with nice cars and so on, it creates a 'them and us' tendency, the development is incongruous with the surrounding area and conspicuous. (Resident outside GC)

There was more ambivalence about the degree of isolation of GC residents from local areas. Some neighbouring residents suggesting that they didn't have any problems with GC residents per se but, rather, it was the nature of the development and the idea that other types of provision (housing or local services) were being lost:

The development is ugly, and is referred to locally as 'Fort $\mathrm{X}$ ' but the community was not concerned about the type of people moving into the development, the concern was more about the further erosion of a greenfield site. There is no adverse feeling towards the residents of the gated community, it is 'just there', and if people choose to live in it, then that is up to them. (Chairperson of Neighbouring Residents' Association)

In general, despite the recognition of processes of exclusion and distinction, the attitudes of neighbouring residents towards gated community residents themselves appeared to be characterised by resignation, neutrality and a lack of awareness, rather than hostility. One local community police officer said that his 'gut feeling is that there is rivalry between the gated and non-gated factions, although I am not sure if this translates into overt antagonism'. The case studies found no evidence of any direct antagonism towards the gated developments. In one case study, gated community residents reported an on-going issue about 
local children from neighbouring housing areas trying to access the play areas within the gated development, but it was not possible to establish how this was regarded more widely in the local community. Such frustration was usually not directed at the residents of the GCs themselves:

There is no adverse feeling towards the residents of the gated community. It's just there, and if people choose to live there that is up to them. It is neutral in its impact apart from being physically unattractive. (Chairperson, Neighbouring Residents' Association)

Although such ambivalence was not uncommon other outcomes appeared which might have wider consequences to the surrounding locale. Gated residential development provides a terrain on which many outside key actors, such as planners, and residents found an intuitive sense of dislike. Many of these GCs were seen as 'hidden dormitories' with social segregation exaggerated by spatial segregation. In some cases GC residents themselves appeared to be concerned about the possibilities for withdrawal and division that such developments created:

They can be viewed as providing security to only one type of people, those who can access safety through paying money, which excludes disadvantaged groups who do not have this option. There is the ultimate scenario of secure affluent gated communities surrounded by chaos. In some sense gating is a sign of failure, and the government should not be looking to gate everywhere. Ideally no development should have a gate. This requires greater policing or resolving the crime problem, which may require putting up taxes, but people are reluctant to accept this, but gating can be seen as the final resort when all else has failed. (GC resident)

Many expressed concern that GCs were not adequately integrated, physically or socially, into the local area. As one planning officer put it: 'Gated communities are separated and isolated from the rest of the community. They are clearly not part of the fabric of their local areas.' The case study GCs were viewed as exclusive, both by residents within the developments, and by the residents of surrounding neighbourhoods, who largely viewed the residents of the gated communities, in the word of the Chair of one local residents' association, as 'those people behind the gates.'

This lack of integration was partly the result of the exclusive nature of the gated communities, and this distinction in the view of many respondents, was deliberately generated by both developers and the residents of the communities:

The developments were created as separate entities and regard themselves as entirely separate from the local area, and indeed pride themselves on having unique attributes in distinction from surrounding areas. (Planning Officer)

However, the resulting lack of social interaction and cohesion seems to concern the residents of gated communities themselves. One resident reported that they would not have chosen to live in their development if they had realised the extent to which it was cut-off from the locality. The physical security features of the developments contribute to this exclusive image as one gated community resident put it: 'The gates are intended to convey a message to the 
wider community' while a planner referred to a 'lord of the manor syndrome'. This message of exclusion was exacerbated by the physical dislocation of many developments from nearby housing and were often viewed as physically unattractive by neighbouring residents with a sense of separateness from both the life and local architecture of the area.

In some areas gated communities were built on the existing high status and affluence of the surrounding area so that the extra degree of privatisation offered by the GC was not considered out of place. There was some regret in other areas that former public buildings had been used for exclusive private developments. For example, in Lambeth we found that one of the developments had been a school and there was local resentment that this had not been kept as what representatives saw as public assets. Similar feelings were expressed in our northern town case study:

It is a nice building which could have been used as a stately home for the National Trust to let the public enjoy the grounds and buildings. So it is a shame access is prohibited ... It's certainly a lovely place which is a loss to the public. (Neighbouring resident, Chester le Street)

This perception of 'separate worlds', 'isolated communities', or 'social islands' was reported by respondents to extend to GC residents not using local shops or leisure facilities. Others reported that a limited number of GC residents utilised local shops, and in one development, a number of residents were reported to frequent a nearby public house used by neighbouring communities. However, the importance of work patterns to the dynamics of gated communities and the fragility of their residents' relationships with wider neighbourhoods was evident, both in relation to longer-term residential stability and daily interaction, as demonstrated here:

There is a big 'no' to interaction between gated community residents and other local residents. It's all about the commuting lifestyle. (Local Community Police Officer)

And;

The residents of the gated community come there for work reasons and many may not be there that long. They keep themselves to themselves. (Gated community resident)

In the case study GCs where services were located on-site this meant that residents had even less need to venture beyond the gates, further isolating them from surrounding areas. The finding here is that the spatial trajectories of GC residents were segregated at a series of points in their repeated daily patterns of movement-in their shopping, leisure, schooling and home life which were cut-off from the wider community and which did not bring economic benefits to the local area. The observation from outside was that GC residents were not integrated locally:

These people haven't integrated with the local community ... Money there doesn't get spent here and they are not involved in the community. There is a Tesco's Express nearby so the local shops haven't seen any benefit. (Outside tenant representative) 
The residents of GCs supported this view: 'We don't have any particular links with the outside world but people here are outward looking. There are some clubs but it is not a vastly social place' (Gated resident association member).

This lack of contact extended to more formal local structures. Representatives of local community or residents' associations reported that few members of nearby gated communities were members of these associations, despite their eligibility. In part this is a result of the well-developed residents' associations within the gated communities, but this lack of formal contact caused frustration amongst outside local organisations and with local authority service providers.

Given that GCs almost exclusively cater for affluent households the divisions they create are similar to those within a generally privatised lifestyle marking out middle-class social networks more widely. As residents of the GCs sometimes noted, people went to work and came back in the evenings and didn't communicate with their neighbours or those outside. To some extent the existence of gates may be an artificial distinction in this regard, with neighbouring generally low down the list of social priorities for these groups. However, such evidence appears to contradict the idea that GCs contribute to some communitarian ideal of local interaction and support with like-minded people.

In considering the rationales for the development of GCs and the lifestyles they appear to promote we have sought to develop a commentary on these social forms which takes in the wider nature of fear and segregation in the urban context. We now turn to consider the wider implications of GCs for an understanding of social separation that moves beyond static representations of residential segregation.

\section{Time-Space Trajectories of Segregation-the Fluid Separation of Cities and Space}

Graham \& Marvin (2001) have argued that much of the technological and networked infrastructure being put in place in many cities supports what they term premium network spaces. By this they mean the connection of urban spaces so that wealthy groups are increasingly withdrawn from the wider citizenry. As examples they supply details of shopping malls and hotels accessible only by car, private toll roads and biometric express routes for passport holders. They also view these connected spaces as secessionary, or secluded, from those who are unable to pay or access this technology. In fact Graham and Marvin provide the language needed to understand gated communities as protected nodes in a wider network that create a counterpart city with flows of affluent residents moving while cloaked from the observation of the majority of residents.

In crime pattern theory (Brantingham \& Brantingham, 1981) 'nodes' are used to refer to places where people travel to and from with offenders seeking targets around personal activity nodes and the 'paths' between them. The pattern and location of crime is thereby linked to the environmental structure and opportunities provided by particular spaces. Finally 'edges' are used to describe the boundaries of nodes, such as places of work, shopping or residence. Also important in crime pattern theory is an understanding of the flow of people in relation to the patterns of criminal activity. In combination with Graham and Marvin's views of secessionary spaces it is possible to see the structure of segregation implicated by gated residential developments 
as territories within a wider network precisely delimited in order to avoid creating paths and nodes vulnerable to victimisation.

So far we have looked at the attributed motivations of GC residents and highlighted their patterns of disengagement from the localities they live in. However, we have also remarked that such segregation and privatised modes of living are a relatively unremarkable feature of affluent communities more generally. We now examine the extension of this separation more closely such as it extends outside the GC. As we argued earlier residential patterns of segregation might be considered a more problematic influence on social cohesion if such partitioning also operates through the spatial trajectories, roles and daily lives of residents of GCs in other spaces of the city.

In the themes identified through the case studies it appeared that GCs could be seen as highly segregated forms of development with residents keeping themselves to themselves both within and outside the development. An emphasis on work, long hours and regular relocation, provided a recurring theme as detailed by residents and those outside the GCs who regarded this as a barrier to social interaction, both within and beyond the GC. This was attributed to the 'international' lifestyle of residents, many of whom worked for multinational companies, and were foreign nationals who were likely to reside in the UK for short periods. However, even in the on-street GC in our small town case study such patterns of separation were remarked upon by residents outside the GC.

\section{Spaces of Segregation}

In developing an account of what we see as dynamic forms of segregation we have tried to consider a typology of the locales involved and the impact this has on the seclusion and shielding of the affluent from the wider urban population. What we are attempting to provide is a conceptual mapping of the tendencies in social relationships produced by gated communities. However, we feel that there is a wider application of these tendencies to most attempts to shield, insulate and otherwise embrace strategies that promote social separation. Fundamentally we see the route of these strategies in a fear of crime but also of contact with 'others' which might be applied as much to middle income as to upper income households.

We suggest that there are two locations for segregated social action and a third domain referring to the mode of movement between these nodes:

1. Territories-The residential neighbourhoods which, in this case, are defended through design or other technologies (CCTV, security). These spaces are territorial precisely because they are shielded, but this may also be linked to a sense of home or domesticity that creates feelings of ontological security.

2. Objectives-The non-residential locations to which people travel on a daily basis or through repeated patterns of movement which suggest a targeted movement through space rather than a casual, or chance, visit. These spaces may include the workplace, leisure spaces and the social network destinations of friends and kin. Reaching the objective space may lead to feelings of relief or satisfaction in relation to the nature of the journey to them and the relative feelings of threat encountered on the way. Objective spaces may also be fortified (security guards at office receptions) or secluded (underground car parks). 
3. Corridors - these refer to modes of travel which suggest an attempt to shield or to immunise against casual or dangerous encounters. This may include the use of cars over small distances (the school run), first class train or air travel, taxis, separate VIP airport lounges or even anonymous modes of dress designed not to attract attention or serve as a mark of distinction (the office suit or long overcoat). We stress here that the aim is of separation but that this might not always be achievable.

The shielding of spatial patterns of movement for residents through 'corridors' could be observed in our case studies of the GCs. GCs are well designed for car owners and respondents in our research suggested that gating was often in place to prevent car theft. Our structured observations of the GCs indicated an inclination towards car use. Cars generally act as barriers to social interaction but are also designed to promote feelings of safety among larger vehicles as seen in the use of safety messages in advertising which has extended rural and urban survivalist subtexts for sports utility vehicles and the luxury car market.

In its extreme form the only remaining public realm for residents of GCs (and perhaps many upper income households more generally) may be the space between the car and the shop or office door (itself sometimes with controlled access). Car adverts featuring disaster, urban decay and 'strange people' outside amplify the sense of interior space as one of calm and security for the driver, often emphasised by the presence of a child passenger. Market research enabling psycho-social linkages to be made between the drivers of demand for GCs and these modes of transportation (Bradsher, 2000) claims that sports utility vehicle owners are 'insecure, vain, lack confidence in their driving skills, are self-centred and have little interest in their neighbours and communities' (Mencimer, 2002).

This trend in car consumption and the desire for security and safety that underpins it is illustrative of the sheltered connections between GC territories and destinations that we propose here. We would suggest that this privatisation of mobile space is used to support an infrastructure of trajectories of segregation-connecting security patrolled shopping centres, workplaces, CCTV covered and gated parking and gated private schools. A resident of one of the larger and more affluent case study GCs identified these processes:

There is excellent security. But the most important factor is the presence of work and schools locally. A lot of the properties are rented by families from the US who send their children to the two local American schools. There are also a number of individuals from Hong Kong. The location of the development is ideal for these schools and for accessing the headquarters of a number of large multi-national companies which are located nearby. It is as simple as that, work and schools are the main reason for residents choosing to live in the development. The development is also well situated for families with children who want to use local rail links.

Meanwhile a neighbouring resident of a smaller gated community in the north of England commented similarly that:

They [GC residents] live in a separate world and don't seem to spend a lot of time here because of the type of work they do, they are always away, I think they just use their flats as crash pads. There seems to be an aversion to community activity, I wouldn't know who lived 
there ... I don't have anything to do with the people because you don't see them walking anywhere and they don't seem to be here much.

These various nodes are linked by patterns of movement which are detached from their social contexts, promoting a cognitive map of the city inhabited by like-minded individuals that generate socially homogeneous contact absent of potential threats and encounters. The dependence on, and use of, cars can be seen as an extension of gating and what we term 'bubbling' - the orchestrated management of perceived risk spaces and social contact while moving around the public realm in shielded corridors. We already know that key social groups (such as women and young men) have cognitive maps of urban spaces that affect the probability of selecting certain paths through the city based on perceptions of risk. However, when bubbling is combined with affluence, technologies of surveillance and enclosed transportation the effect is a wider withdrawal from the public sphere.

However, incursions into these corridors and the puncturing of attempts to create such 'bubbles' are always possible and present themselves as ever-greater risks to those living in gated areas. While people felt safe within the GC they were more exposed if moving on foot outside, as one respondent pointed out: 'It's a bit risky here, but at the end of the day you need to walk to get to your gated community, if you see what I mean.' The use of cars to leapfrog these encounters highlights a dynamic form of segregation in which trajectories through space are disconnected from the local area.

\section{Conclusions}

This exploratory paper has tried to look at the wider significance of gated communities in England. The discovery of around one thousand such developments suggests their growing popularity as well as patterns of interaction and separation which imply an attempt to reduce fears of victimisation and promote privacy. We have tried to link these patterns to a reconceptualisation of residential space which extends beyond gated communities in which the attempt to create shielded or 'secessionary' spaces of withdrawal has allowed affluent households to appear as though they have almost disappeared from the public realm in many cities. In short, these attempts at social extraction strike a chord with wider attempts at security by middle income groups while gated communities suggest these processes in extremis.

We have tried to suggest that two aspects of gated communities may be particularly significant. First, that they may have strong symbolic aspects linked to a fear of crime and dystopian images of future city changes and public social relationships.

Second, gated communities are growing at a time when urban policy prescriptions are moving towards development and interventions promoting sustainability based on mixed use, revitalised public spaces and environments that promote social contact, tolerance and political engagement. We would argue that if policy-makers believe that residential segregation and homogeneity are perceived to be problematic for deprived areas it is difficult to continue to turn a blind eye to the withdrawal of middle and upper income households into their own ghettos. If this premise can be accepted then the idea of dynamic patterns 
of separation and disaffiliation may be seen as even more intransigent social problems that require further research and analysis.

Arguably gated communities and current urban policy seek similar ends, namely the promotion of the city as a place to live for the middle classes. In this the small scale and number of GCs helps in a case for their immunity from wider planning frameworks. It is possible to argue that they cater for an elite fraction who need security by virtue of their status and that security is a right to which freedom of choice should be ascribed. However, our case studies suggest that GCs range from off-street flatted units in small northern towns to feudal fortresses on huge sites implying a much wider market appeal and that a wider demographic is seeking this kind of spatial withdrawal.

In drawing on the theoretical work of several writers we have tried to develop a conceptualisation of residential geography which encompasses social distinction and segregation as an extended movement across time-space. We suggest that residential location and patterns of travel to work and leisure locations can be seen as tunnel-like trajectories separating class and status categories. Using the example of gated communities we can see repeated patterns of movement between gated enclaves, the use of on-site shops, high car dependence and 'shielded' travel with the use of institutions, workplaces and schools which are also secluded from people 'not like us'.

Gated developments extend the feudal character of urban contact. This goes even beyond Smith's (1996) argument that middle class urban homesteading and domestication through gentrification represents an attempt to tame the urban frontier with its own pioneers. In fact GCs may be less about taming and more a display of an early endgame in which 'respectable' families have opted finally for withdrawal, acknowledging that the city cannot be predicted or tamed.

We are guarded in our attempt to push the notion of a time-space trajectory of segregation more widely, but there are reasons to believe that this is not limited solely to residents of GCs. The need for safety and security and the imperative of like-with-like social contact in residential environments are important drivers of spatial segregation but also the patterns of daily movement to which people commit themselves. Risks such as crime, poor environment and unwanted social contact are managed by people rather than being simple random outputs of trajectories between nodes. The spatial refuge of the gated development can also be viewed as a cognitive shelter. As sensitivities to contact with outsiders increase, the imperative to shield becomes greater with strategies employed to manage the exposure to perceived risks and desired social contact and spatial environments. What this suggests is that 'forting up' (Blakely \& Snyder, 1999) is not restricted to GCs and is being expressed through a range of defensive intentions applied to transportation, workplaces and neighbourhoods. These changes are not only related to the risk of crime but also to the high value ascribed to privacy, quiet and an absence of social contact, themselves seen as badges of status.

GCs also connect with wider issues about the openness of cities, their transparency and accessibility. Mixed use development and living in open and diverse social areas lie at the heart of a system which increasingly seeks to integrate a wider range of social backgrounds in locales and which is challenged by the existence of gated enclaves which constrict the free movement of strangers. 
The spatial revolt and withdrawal of the elites through GCs appears to be an attempt to escape the 'gravity' of democratic social relationships. However, these private residential choices have a series of real impacts on wider society. As Galbraith noted in The Affluent Society (1958), private affluence may be linked to the squalor of the public realm and this retreat to fine homes and gated neighbourhoods may also be matched by equally disappointing encounters with their surrounding untended public spaces. The costs to wider society are amplified by the extension of segregatory time-space trajectories as a response to these encounters.

As Smith (1996) argues, the frontier myth of urban taming produces an ideology that rationalises social exclusion as both natural and inevitable. The conceptualisation of gating as representing natural and irreversible forces needs to be challenged. The relatively small number of GCs in England does not diminish this need. In the British context a gated community increasingly presents a highly privatised mode of living which also appears to be expressed beyond the gates. An exponential proliferation of spatially separate fiefdoms with internal governance arrangements, and self-taxation may only be a dystopian image at present. However, the precedent set by GCs moves us in this direction which may continue a divisive ratcheting-down of social relations.

\section{Acknowledgement}

This paper is based on research carried out with colleagues from Sheffield Hallam (Sarah Blandy) and Cambridge (Diane Lister) Universities.

\section{Correspondence}

Rowland Atkinson, Department of Urban Studies, University of Glasgow, 25 Bute Gardens, Glasgow G12 8RS, UK. Email: r.atkinson@socsci.gla.ac.uk

\section{References}

Amin, A., Massey, D. \& Thrift, N. (2000) Cities for the Many not the Few (Bristol, Policy Press).

Atkinson, R. \& Kintrea, K. (2002) A consideration of the implications of area effects for British housing and regeneration policy, European Journal of Housing Policy, 2(2), pp. 1-20.

Atkinson, R. \& Kintrea, K. (2004) 'Opportunities and despair, it's all in there': practitioner experiences and explanations of area effects and life chances, Sociology, 38(3), pp. 437-455.

Auge, M. (1995) Non-places: Introduction to an Anthropology of Supermodernity (London, Verso).

Baumgartner, M. (1988) The Moral Order of a Suburb (New York, Oxford University Press).

Blakely, E. \& Snyder, M. (1999) Fortress America: Gated Communities in the United States (Washington DC, Brookings Institution).

Bradsher, K. (2000) Was Freud a minivan or S.U.V. kind of guy?, New York Times, 17 July.

Brantingham, P.L. \& Brantingham, P.J. (1981) Notes on the geometry of crime, in P.L. Brantingham \& P.J. Brantingham Environmental Criminology (Beverly Hills, Sage Publications) pp. 27-54.

Bridge, G. \& Watson, S. (2000) City publics, in G. Bridge \& S. Watson (Eds) A Companion to the City (Oxford, Blackwell).

Crawford, A. (1997) The Local Governance of Crime: Appeals to Community and Partnerships (London, Clarendon).

Davis, M. (1998) Ecology of Fear: Los Angeles and the Imagination of Disaster (London, Picador).

Ellen, I. \& Turner, M. (1997) Does neighbourhood matter? Assessing recent evidence, Housing Policy Debate, 8(1), pp. 833-866.

Fainstein, S., Gordon, I. \& Harloe, M. (1992) Divided Cities: New York and London in the Contemporary World (Oxford, Blackwell). 
Galbraith, J.K. (1958) The Affluent Society (London, Pelican Books).

Goldberger, P. (1996) The rise of the private city, in J. Vittullo Martin (Ed.) Breaking Away: The Future of Cities (New York, The Twentieth Century Fund).

Graham, S. \& Marvin, S. (2001) Splintering Urbanism: Networked Infrastructures, Technological Mobilities and the Urban Condition (London, Routledge).

Hannigan, J. (1998) Fantasy City: Pleasure and Profit in the Postmodern Metropolis (London, Routledge). Harvey, D. (1990) Between space and time, in Annals of the Association of American Geographers, 80, pp. $418-434$.

Hope, T. (1995) Community crime prevention, in M. Tonry \& D. Farrington (Eds) Building a Safer Society: Strategic Approaches to Crime Prevention (Chicago, University of Chicago Press).

Lasch, C. (1996) The Revolt of the Elites and the Betrayal of Democracy (London, Norton).

Low, S. (2003) Behind the Gates: Life, Security, and the Pursuit of Happiness in Fortress America (London, Routledge).

Massey, D. \& Denton, N. (1998) American Apartheid: Segregation and the Making of the Underclass (Boston, Harvard University Press).

McKenzie, E. (1995) Privatopia: Homeowner Associations and the Rise of Residential Private Government (London, Yale University Press).

Mencimer, S. (2002) Bumper mentality, Washington Monthly, 20 July.

Minton, A. (2002) Building Balanced Communities: the US and UK Compared (London, RICS).

Musterd, S. \& Ostendorf, W. (1998) Urban Segregation and the Welfare State: Inequality and Exclusion in Western Cities (London, Routledge).

Peach, C. (1996) Does Britain have ghettoes?, Transactions of the Institute of British Geographers, 12(1), pp. 214-235.

Reiner, R. (1992) The Politics of the Police, 2nd edition (Hemel Hempstead, Harvester Wheatsheaf).

Sennett, R. (1970) The Uses of Disorder: Personal Identity E City Life (New York, Knopf).

Sennett, R. (1977) The Fall of Public Man (Cambridge, Cambridge University Press).

Sennett, R. (2000) Reflections on the public realm, in G. Bridge \& S. Watson (Eds) A Companion to the City (Oxford, Blackwell).

Shearing, C. (1995) Reinventing policing: police as governance, in O. Marenin (Ed.) Policing Change: Changing Police (New York, Garland Press).

Smith, N. (1996) The New Urban Frontier: Gentrification and the Revanchist City (London, Routledge). 